\title{
Editor's Note (read it this time, please)
}

A journal is rather like a house plant: unless it is an artificially vibrant silk or plastic creation, a journal grows, changes, and needs care and attention. Each issue sits like a border plant along the path of time. A journal is watered and fertilized by submissions, pruned by editing, and fed by peer review. It sits in the sun of a readership. When any of that nourishment is cut back, the journal withers.

Part of an editor's job is to look ahead, to see where the journal is growing and where there remains room for growth. Part of looking ahead also involves looking back across the path forward that has already been walked, to look over where we have been, to see if we are still on course and moving in the direction we want to go and toward something we still see as a goal.

As the editor of what I hope is your regular professional reading, I have paused along the path, looked backward and ahead for my bearings, and can report that the journal is doing relatively well. You can see in the topically diverse articles and reviews in this issue that interesting topics and new technologies concern your peers, and that means there are opportunities for viewpoints, activities, and conclusions that merit attention and comment. As these writers have done, I encourage you to go out on a limb and talk about something you may have tried or things that you may do regularly. Look for a new way to compare or apply what you have learned, and tell the rest of us about it. Your profession and this journal need you, specifically.

As I look back across where the journal has come from since its founding as Rare Books and Manuscripts Librarianship in 1986, I also notice a few things are missing. I see very little about addressing the needs of physically challenged patrons in exhibits or reader service. There is virtually nothing about the challenges, practices, or concerns of special collections in historically black colleges and universities, and there is nothing from or about tribal colleges. Very, very little appears on the subject of service in rurally isolated institutions. Folks, we can do better individually and as a profession.

I very much encourage people with experience in fields like those above to help the rest of us understand what part of the profession is either similar to or different from 
what the rest of us do. To that end, I hope you will note elsewhere in this issue the call for submissions for a topical issue of RBM in the fall of 2019 to address the challenges, opportunities, and practices in the cultural corners of special collections outside the mainstream. If you are looking for writing ideas, here are a few that occur to me:

- A discussion or collection of comments interpreting special collections librarianship from practitioners who are something besides white and female (our statistical majority) and who work with collections in other than large or fairly large institutions.

- The challenges and opportunities of equitably documenting and representing local cultural minorities within an otherwise mainstream institutional collection.

- The difficulties of documenting non-English linguistic populations.

- Dealing with culturally sensitive artifacts within collections.

- Identifying, documenting, and interpreting forgeries and counter-histories or narratives.

- The intricacies of handling materials that challenge cultural memory when the latter does not square with documentary records.

These are examples of possibilities, not specific requests; I'm sure you have thoughts of your own. We need thoughtful, engaged articles on the HBCUs and tribal colleges, on cooperation between institutions, about pitfalls and best practices for material beyond the mainstream. Without those voices and subjects on record, the community may be vibrant, but its professional literature remains incomplete.

\section{Call for Submissions}

The editor invites submissions for a thematic issue of $R B M$ in the fall of 2019 entitled Minority Report: Practice and Issues beyond the Mainstream.

The issue seeks submissions documenting and discussing special collections and manuscripts practice dealing with:

- Historically black colleges and universities

- Tribal and First Nations colleges

- Cultural and linguistic minorities

- Marginal and subaltern populations

- $\quad$ Isolated non-English materials

- Cultural artifacts within collections

Manuscripts should follow standards listed on the submissions page at http://rbm.acrl.org/index.php/rbm/about/submissions.

Submissions intended for the issue must be received before June 2019.

Please direct inquiries to the editor: Richard Saunders, rsaunders@suu.edu. 